\title{
Experimental chronic compression on the spinal cord of the rabbit by ectopic bone formation in the ligamentum flavum with bone morphogenetic protein
}

\author{
Kentaro Mimatsu, Seiichi Kishi and Yoshio Hashizume \\ Department of Orthopaedic Surgery, School of Medicine, Nagoya University, 65, Tsuruma-Cho, Showa-Ku, Nagoya, \\ 466 Japan
}

\begin{abstract}
This study was conducted to induce chronic spinal cord compression myelopathy in rabbits. The L5 lumbar lamina was cut partially in 70 rabbits, and bone morphogenetic protein (BMP) was implanted on the ligamentum flavum in 35 of them. In the BMP group, new bone formed on the dorsal side of the spinal canal and flattened the spinal cord in an anteroposterior direction. No pathological changes were detected in the intramedullary tissues by light microscopic examination. In rabbits it is possible to induce compression of the cord by using BMP, although sufficient cord compression to induce myelopathy was not achieved.
\end{abstract}

Keywords: BMP (bone morphogenetic protein); chronic spinal cord compression; myelopathy; spinal cord; ligamentum flavum

\section{Introduction}

Various forms of cervical myelopathy including cervical spondylotic myelopathy, ossification of the posterior longitudinal ligament (OPLL) and calcification of the ligamentum flavum are important conditions in the field of spinal disease and its treatment. However, because the symptoms associated with these conditions develop slowly, insufficient information is available on the relation between the degree of spinal cord compression and degree of myelopathy or on the pathophysiology of myelopathy.

Numerous studies on the experimental compression myelopathy using animals have appeared in the literature. Most of these have been acute spinal cord compression experiments, although some chronic spinal cord compression experiments have also been performed. In most cases, mechanical compression has been applied from the anterior cervical vertebrae using foreign bodies such as bone fragments, ${ }^{1}$ screws, ${ }^{2}$ or silicone rubber. ${ }^{3}$ Experiments in which compression was induced by implantation of tumor tissue or fetal stage kyphotic deformity of the spine have also been undertaken, although the compression resulting in these cases bears little resemblance to the clinical features of the above-mentioned conditions, which are characterized by the gradual development over long periods of bone-induced biological compression. BMP (bone morphogenetic protein) which we used is found in normal bone tissue and is a bone inducing

Correspondence: Dr Kentaro Mimatsu substance. It induces new bone formation in an ectopic site by a process of enchondral ossification. ${ }^{4}$ BMPs are a subset of the transforming growth factor (TGF- $\beta$ ) superfamily of dimeric, disulfide crosslinked growth and differentiation factors. At least six human BMPs have demonstrated: BMP 2, -4, -5, -6, -7 (OP-1) and -8 (OP-2). ${ }^{5}$ Also referred to as osteogenic protein. The availability of recombinant BMPs has permitted definitive test of their osteoinductive activity in a variety of experimental systems, including several animal models of clinically relevant bone defects. BMP-induced formation of cartilage and bone in vivo is clearly a complex and multistaged process. ${ }^{6}$ Our purpose in the present study was to accelerate ossification of the ligamentum flavum over a period of several months using bone morphogenetic protein $(\mathrm{BMP})^{7}$ extracted from rabbit long bone, and to examine the state of posterior chronic spinal cord compression in rabbits.

\section{Methods}

\section{Experimental animals}

Seventy adult rabbits each weighing $2.6-3.3 \mathrm{~kg}$ were used and were divided into a BMP group and control group. The former consisted of 35 rabbits in which BMP was implanted on the ligamentum flavum at L56 , while the latter consisted of 35 rabbits undergoing the same surgical manipulations but without BMP implantation. Both groups of animals were maintained in rabbit cages. 


\section{Extraction of BMP}

BMP was extracted from the long bones of Japanese white rabbits according to the method of Hanamura et $a l .{ }^{8}$ Sterilization was achieved using ethylene oxide gas.

Prior to the implantation of BMP, a portion of the crude BMP was implanted into mouse femoral muscle, and used only after confirming two weeks later that bone formation had occurred.

\section{Surgical methods}

The animals were injected i.m. with atropine sulfate $0.1 \mathrm{mg}$ followed by i.v. injection of Nembutal $30 \mathrm{mg} /$ $\mathrm{kg}$. When body movement was still detected inhalation anaesthesia by ether was added. After induction of anesthesia, the animals were fixed in the prone position on a rabbit experimental restraining board and an approximately $3 \mathrm{~cm}$ longitudinal skin incision was made over the lumbar spine. The dorsal paravertebral muscles were detached with an electric scalpel, and the spinal process of L5 was resected at its base. Next, the ligamentum flavum was exposed at L5-6. At the attachment of the ligamentum flavum to the lamina of L5, a groove was cut into the lamina using a surgical drill under microscopic control. A thin layer of ligamentum flavum was left at the base of the groove, and care was taken not to subject the dura or spinal cord to direct influence from the operation. In the BMP group, powdered BMP $1.0 \mathrm{mg}$ was placed in the portion surrounded by the groove and ligamentum flavum and covered with free muscle fragments (Figure 1). In the control group BMP was not inserted.

The rabbits were sacrificed with $5 \mathrm{mg}$ of Nembutal injected i.v. 4, 8, 12, 16, 24 and 40 weeks after operation. Immediately after cardiac arrest L5 and L6 were removed as a block and fixed in $10 \%$ formalin. After decalcification in Prank-Rycro fluid, transverse specimens of the spinal canal were prepared.

The transverse specimens, after stereoscopic imaging, were embedded in paraffin, and subjected to Hematoxylin-Eosin and Klüver-Barrera staining. From these specimens the volume of newly formed bone, degree of spinal cord deformity and degree of spinal cord compression were recorded. These experiments were performed at the Experimental Animal Research Institute of Nagoya University.

Table 1 Grade of motor palsy

0 : unable to support the body with posterior extremities

1 : able to move by anterior extremities, but unable to support with posterior extremities

2 : able to move unable to jump

3 : able to jump by posterior extremities able to run very slowly

4 : unable to run quickly

5 : normal
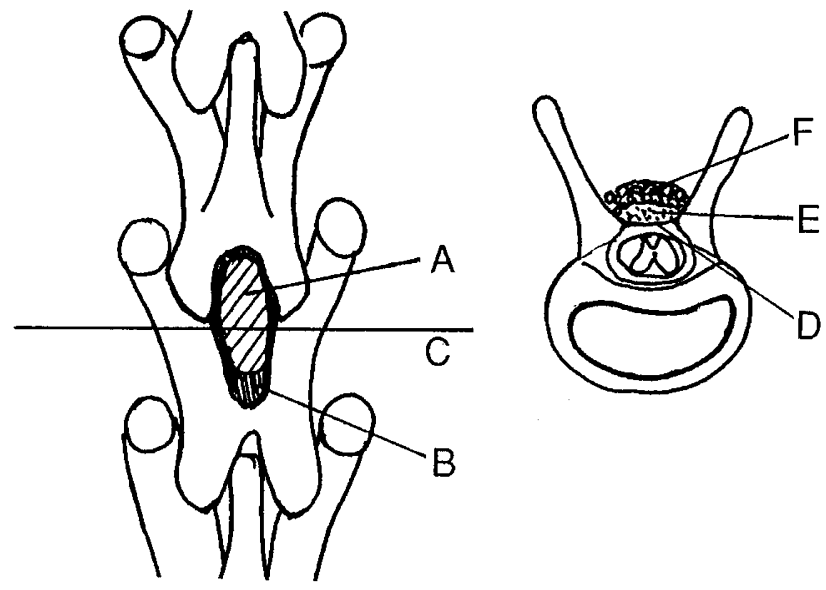

a

b

Figure 1 (a) Rabbit spine of L5 and L6. A: area of placement of BMP, covered with free muscle fragments; B: removal of L6 spinal process. (b) Transverse section at C-line. $\mathrm{D}$ : thin deep layer of ligamentum flavum; E: powered BMP; F: free muscle fragment

\section{Evaluation}

The following parameters were evaluated in each rabbit: weight, number of follow-up days from the operation to sacrifice, presence/absence and degree of motor palsy, presence/absence of sensory disturbance and urinary incontinence, degree of ossification at the operated portion, degree of stenosis of the spinal column, and flat ratio of the spinal cord. Also, intramedullary histological changes were observed with a light microscope. These parameters were compared between the BMP and control groups. Student $t$-test was used for statistical evaluation of the data.

The rabbits were removed from their cages and their gait observed by the three authors. Values about which the opinions of $\geqslant 2$ authors were in agreement were adopted. The criteria for the evaluation are listed in Table 2.

These criteria represent a modification of the classifications of Tarlov $^{9}$ and Frankquist and Schants. ${ }^{10}$ The presence/absence of sensory disturbance was determined by observing the reaction to a pinprick test. Urinary incontinence was judged to be present when the posterior limbs showed urinary soiling. The area of ossification was determined by magnifying the tissue specimens 7.3-fold and measuring the vertical and transverse diameters of the ossified portion, with the area of ossification expressed as the product of these two values. The evaluation of the tissue ossified portion was performed by the three authors values about which the opinions of $\geqslant 2$ authors were in agreement was adopted. The flat ratio of the spinal cord was calculated by dividing the vertical diameter of the cord by the transverse 
Table 2 BMP group

\begin{tabular}{|c|c|c|c|c|c|}
\hline$\#$ & $\begin{array}{c}\text { Body } \\
\text { weight } \\
(\mathrm{kg})\end{array}$ & $\begin{array}{c}\text { Follow } \\
u p(\text { days })\end{array}$ & $\begin{array}{l}\text { Motor } \\
\text { palsy } \\
\text { (grade) }\end{array}$ & $\begin{array}{c}\text { Flat ratio } \\
\text { of cord } \\
(\%)\end{array}$ & $\begin{array}{c}\text { Ossifica- } \\
\text { tion } \\
\left(\mathrm{mm}^{2}\right)\end{array}$ \\
\hline 1 & 2.8 & 140 & 5 & 56.8 & 2.3 \\
\hline 2 & 2.8 & 56 & 4 & 48.7 & 0.2 \\
\hline 3 & 2.7 & 91 & 5 & 47.2 & 8.4 \\
\hline 4 & 2.6 & 86 & 5 & 62.9 & 0 \\
\hline 5 & 3.1 & 59 & 4 & 49.5 & 2.7 \\
\hline 6 & 2.9 & 169 & 3 & 27.0 & 6.6 \\
\hline 7 & 3.2 & 216 & 5 & 60.0 & 19.7 \\
\hline 8 & 2.7 & 49 & 5 & 62.2 & 0 \\
\hline 9 & 2.9 & 63 & 5 & 41.7 & 0 \\
\hline 10 & 3.0 & 30 & 5 & 44.2 & 0 \\
\hline 11 & 2.6 & 86 & 5 & 47.2 & 16.4 \\
\hline 12 & 3.0 & 34 & 5 & 49.0 & 0 \\
\hline 13 & 2.9 & 34 & 5 & 50.0 & 1.1 \\
\hline 14 & 3.0 & 113 & 5 & 51.3 & 0 \\
\hline 15 & 2.8 & 86 & 5 & 41.7 & 0 \\
\hline 16 & 2.9 & 135 & 5 & 54.1 & 0 \\
\hline 17 & 3.1 & 113 & 4 & 48.5 & 5.6 \\
\hline 18 & 2.7 & 176 & 4 & 35.0 & 7.5 \\
\hline 19 & 3.1 & 113 & 5 & 57.9 & 2.0 \\
\hline 20 & 3.1 & 145 & 5 & 62.5 & 30.0 \\
\hline 21 & 3.2 & 154 & 4 & 45.2 & 16.9 \\
\hline 22 & 3.0 & 86 & 4 & 45.5 & 0 \\
\hline 23 & 2.8 & 59 & 5 & 50.0 & 0 \\
\hline 24 & 2.8 & 86 & 5 & 50.0 & 21.0 \\
\hline 25 & 2.8 & 118 & 5 & 51.4 & 13.1 \\
\hline 26 & 2.7 & 139 & 5 & 55.9 & 0 \\
\hline 27 & 2.6 & 142 & 5 & 55.8 & 16.9 \\
\hline 28 & 3.0 & 131 & 5 & 50.0 & 29.6 \\
\hline 29 & 3.1 & 132 & 5 & 43.6 & 0 \\
\hline 30 & 2.8 & 110 & 5 & 46.3 & 0 \\
\hline
\end{tabular}

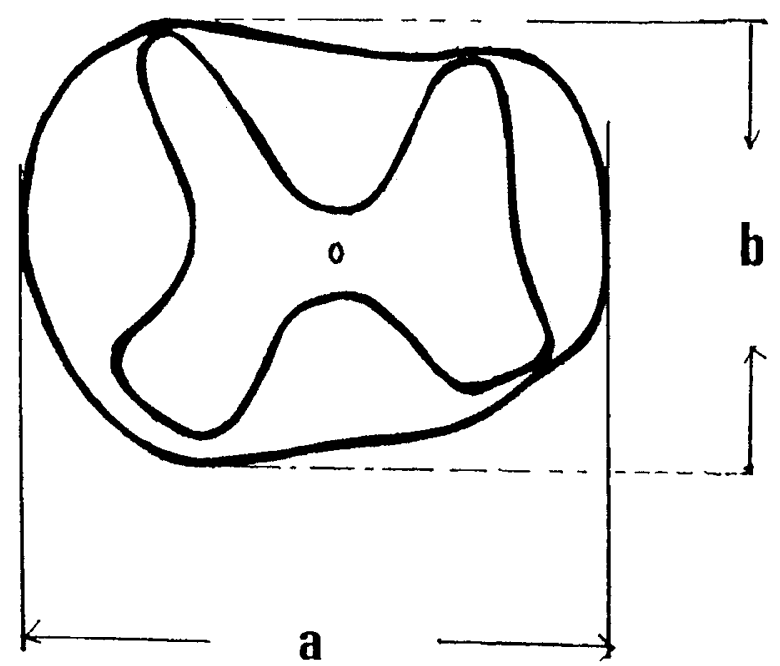

Figure 2 Flat ratio of the spinal cord: $b / a$

diameter (Figure 2). Intramedullary white and gray matter histological changes were observed with a light microscope paying attention to the number of neurons, their state and the presence/absence of a spongy state.

\section{Results}

Experimental animals

Of the 70 rabbits used for the experiments five died within 4 weeks after operation. Ten additional rabbits developed palsy of the posterior extremities immediately after or within 2 weeks of surgery. These complications were attributed to improper surgical technique or to acute spinal cord injury due to postoperative hematoma formation. The data from these animals were excluded, and thus only the data from 30 animals of the BMP group and 25 of the control group were available for the final analysis (Tables 2 and 3 ).

Comparison of the BMP and control groups

Mean weight was $2.89 \pm 0.18 \mathrm{~kg}$ and $2.83 \pm 0.12 \mathrm{~kg}$ in the BMP and control groups respectively. This difference was not significant by $t$-test. The follow-up period was $105.0 \pm 45.9$ and $135.2 \pm 88.3$ days in the BMP and control groups respectively (not significant).

No animal in either group showed palsy to the extent that movement of the posterior extremities was severely affected. In the BMP group, one animal was unable to jump with the posterior extremities (grade 3 ), while six were unable to run quickly (grade 4). The remaining animals showed normal movement. In the control group, five rabbits showed grade 4 , with the remaining animals all showing normal movement. The two groups did not differ significantly with respect to this parameter.

No animal in either group showed results suggestive of sensory disturbance on the pinprick test. No animal in either group showed urinary soilage of the posterior extremities. Thus, urinary incontinence due to abnormal urinary function was not thought to be present in any animal.

The degree of ossification of the ligamentum flavum was estimated to be $6.67+9.29 \mathrm{~mm}^{2}$ in the BMP and $0.34 \pm 0.92 \mathrm{~mm}^{2}$ in the control group, with this difference statistically significant $(P<0.01)$. This finding shows that ossification was accelerated in the BMP group (Figure 3).

The flat ratio of the spinal cord was $49.7 \pm 7.9 \%$ in the BMP group and $56.8 \pm 9.6 \%$ in the control group, with this difference statistically significant $(P<0.005)$. This finding shows that the spinal cord was significantly more flattened in the BMP group as compared to the control group (Figure 4).

In the BMP group, cartilage cells were present in large numbers in the implanted portion $(57 \%$, Figure $5)$, where irregular ossified tissue was formed continuously from the cartilage cells. This ossified tissue consisted of lamellar compact bone in which bone marrow formation was also found. In some 
Table 3 BMP Control

\begin{tabular}{|c|c|c|c|c|c|}
\hline$\#$ & $\begin{array}{c}\text { Body } \\
\text { weight } \\
(\mathrm{kg})\end{array}$ & $\begin{array}{c}\text { Follow } \\
\text { up (days) }\end{array}$ & $\begin{array}{l}\text { Motor } \\
\text { palsy } \\
\text { (grade) }\end{array}$ & $\begin{array}{c}\text { Flat ratio } \\
\text { of cord } \\
(\%)\end{array}$ & $\begin{array}{c}\text { Ossifica- } \\
\text { tion } \\
\left(\mathrm{mm}^{2}\right)\end{array}$ \\
\hline 1 & 2.9 & 91 & 4 & 59.7 & 0.2 \\
\hline 2 & 2.8 & 301 & 4 & 59.5 & 2.4 \\
\hline 3 & 2.8 & 261 & 5 & 41.3 & 0 \\
\hline 4 & 2.7 & 309 & 5 & 51.4 & 0 \\
\hline 5 & 2.7 & 91 & 5 & 52.5 & 0 \\
\hline 6 & 2.7 & 59 & 4 & 45.0 & 2.9 \\
\hline 7 & 2.9 & 101 & 5 & 75.0 & 0 \\
\hline 8 & 2.8 & 263 & 5 & 48.8 & 0 \\
\hline 9 & 2.7 & 30 & 5 & 66.7 & 0 \\
\hline 10 & 2.8 & 169 & 5 & 65.8 & 0 \\
\hline 11 & 2.7 & 113 & 5 & 65.7 & 0 \\
\hline 12 & 3.0 & 56 & 5 & 57.1 & 0 \\
\hline 13 & 2.8 & 59 & 4 & 63.6 & 0 \\
\hline 14 & 2.7 & 40 & 5 & 67.7 & 0 \\
\hline 15 & 2.8 & 170 & 5 & 43.6 & 0 \\
\hline 16 & 3.1 & 168 & 5 & 55.3 & 0 \\
\hline 17 & 3.0 & 281 & 5 & 61.5 & 0 \\
\hline 18 & 3.0 & 164 & 5 & 70.6 & 0 \\
\hline 19 & 2.8 & 164 & 5 & 60.6 & 0 \\
\hline 20 & 2.7 & 56 & 5 & 63.6 & 0 \\
\hline 21 & 2.8 & 129 & 5 & 43.2 & 0 \\
\hline 22 & 2.7 & 105 & 4 & 48.6 & 0 \\
\hline 23 & 3.0 & 30 & 5 & 46.3 & 0 \\
\hline 24 & 2.9 & 129 & 5 & 60.6 & 0 \\
\hline 25 & 3.0 & 40 & 5 & 45.5 & 3.0 \\
\hline
\end{tabular}

portions, calcification and connective tissue proliferation were also observed (Figure 6). The edge of the cut lamina and new bone were partially fused $(17.1 \%)$. After 12 weeks they were completely fused (16.7\%). After 16 weeks the amount of granulation tissue and cartilage cells around the bone decreased. In some cases, new bone was seen to proliferate within the spinal canal $(27.8 \%)$, although in the majority it protruded to the posterior.

In the control group, no cartilage cell proliferation was noted, with only thick granulation tissue covering the operated site. However, a few cartilage cells were found in 4 rabbits. After 16 weeks the amount of granulation tissue decreased.

Light microscopic examination of the flattened cord revealed no clear abnormalities, although in both the BMP and control groups atrophy of the neuron cell body and staining of the neuron nuclei of the gray matter were occasionally observed. In the white matter, no histological findings attributable to ossification-induced compression were discernible (Figure 7).

Study on the BMP group

Twelve weeks or more was needed for the development of a considerable degree of ossification (Figure 8). The degree of ossification tended to increase in parallel with increasing duration after operation (correlation coefficient $r=0.481)$.

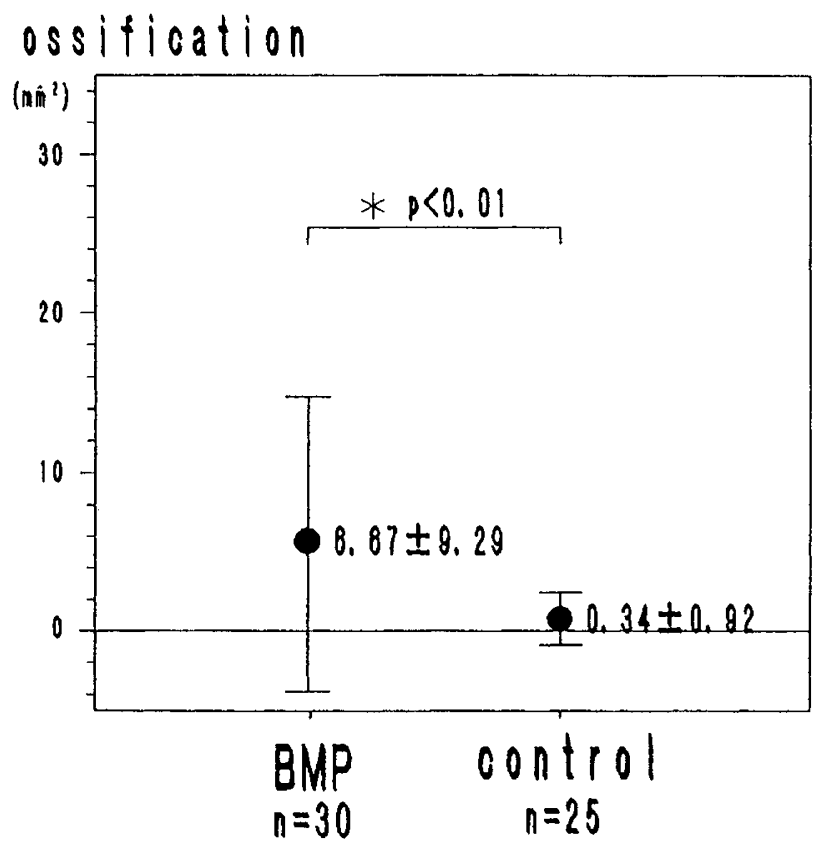

Figure 3 Correlation of ossification area between BMP group and control group. The difference of ossification of the ligamentum flavum between two groups was statistically significant $(P<0.01)$

\section{flat ratio}

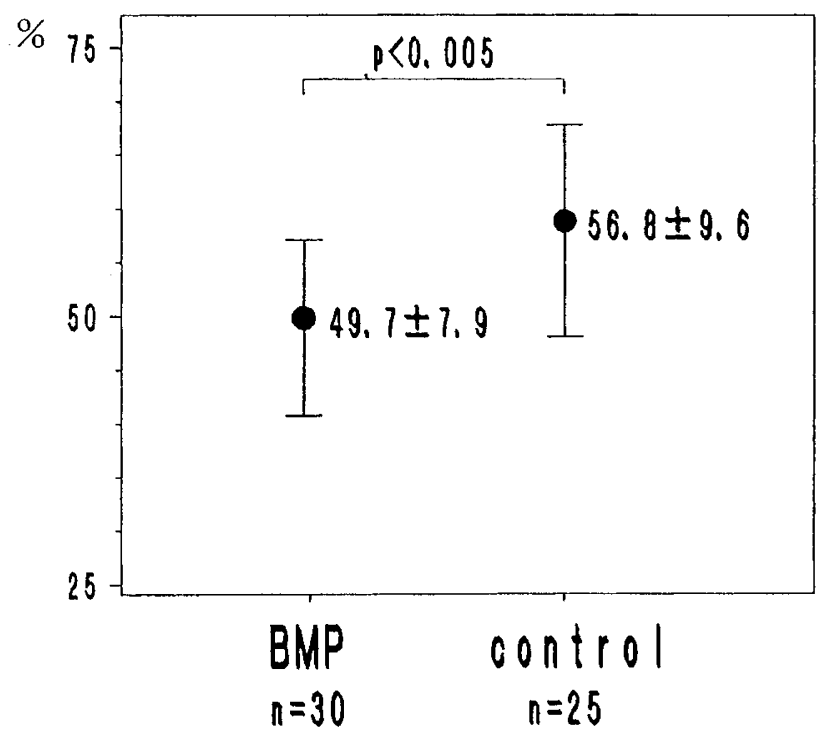

Figure 4 Flat ratio of the spinal cord. The spinal cord was significantly more flattened in the BMP group than the control group

The number of days after operation and cord flat ratio were poorly correlated $(r=0.014)$.

The degree of ossification and cord flat ratio were poorly correlated $(r=0.42)$. This means that although 
BMP induced marked ossification of the ligamentum flavum, the dorsal aspect of the cord was not

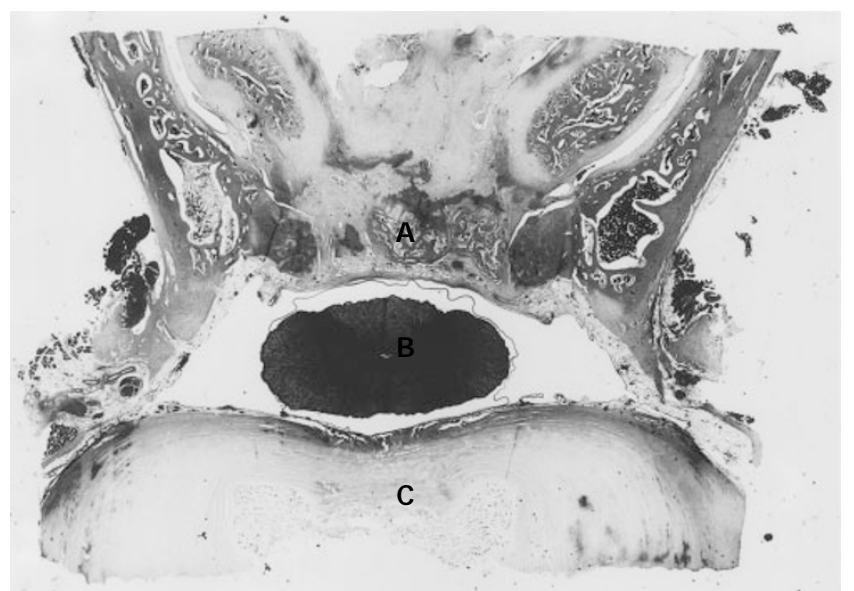

Figure 5 Transverse section of L5-6 in Case \#21. Transplanted area of BMP (A). Compressed spinal cord (B), H.E stained $\times 10$ intervertebral disc $(\mathbf{C})$. Cartilage cells and ossified tissue were seen in the implanted portion of BMP

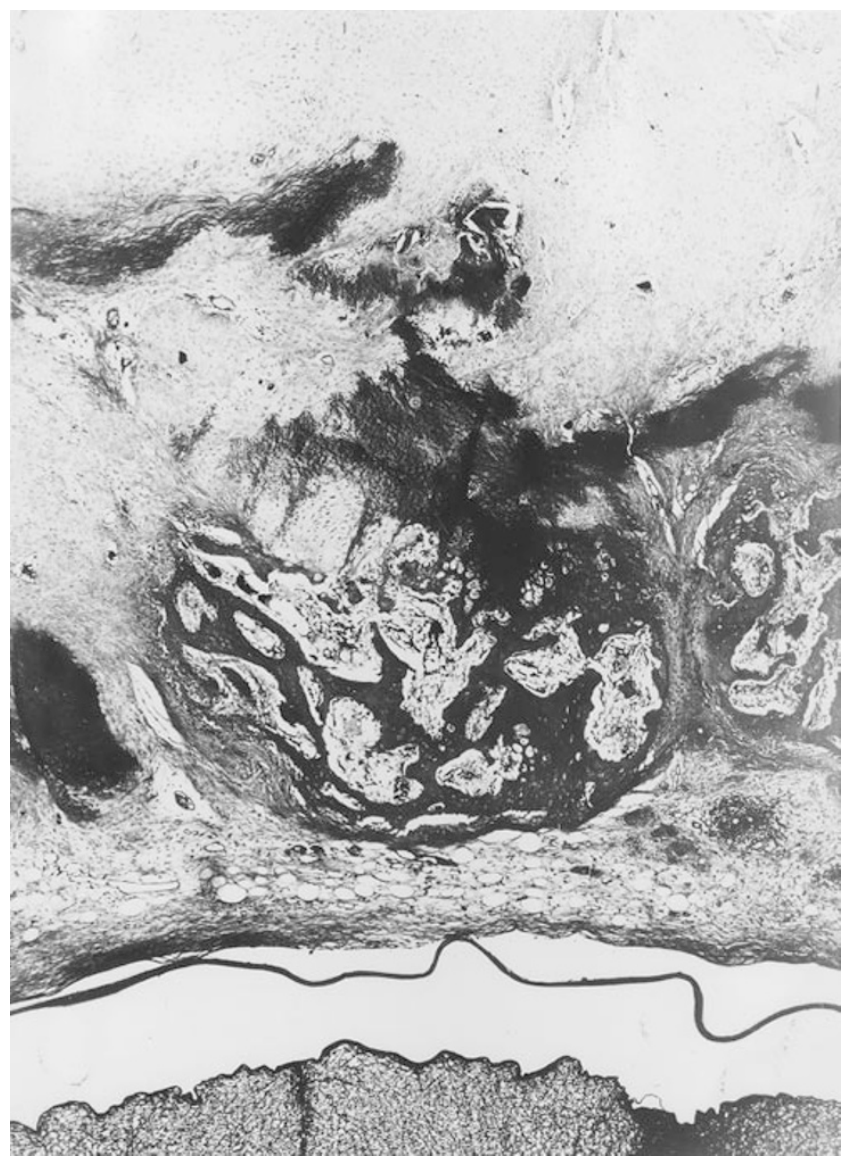

Figure 6 Cartilage and irregular bone tissue were formed in transplanted area of BMP. H.E stained $\times 45$ necessarily significantly compressed even when the ligament was extensively ossified.

\section{Discussion}

BMP, a bone growth stimulating factor that is present in living organisms, is known to induce the differentiation of mesenchymal undifferentiated cells into cartilage cells. It is thought to comprise several types of protein present in bone matrix, most of which are reported to belong to the TGF $\beta$-supergene family. ${ }^{11}$ The members of this family are extracted mostly from cortical bone, and when implanted beneath the fascia induce ectopic bone formation in vivo. ${ }^{7,12}$ BMP has been confirmed in muscle and other organ cultures to induce the differentiation of undifferentiated mesench-

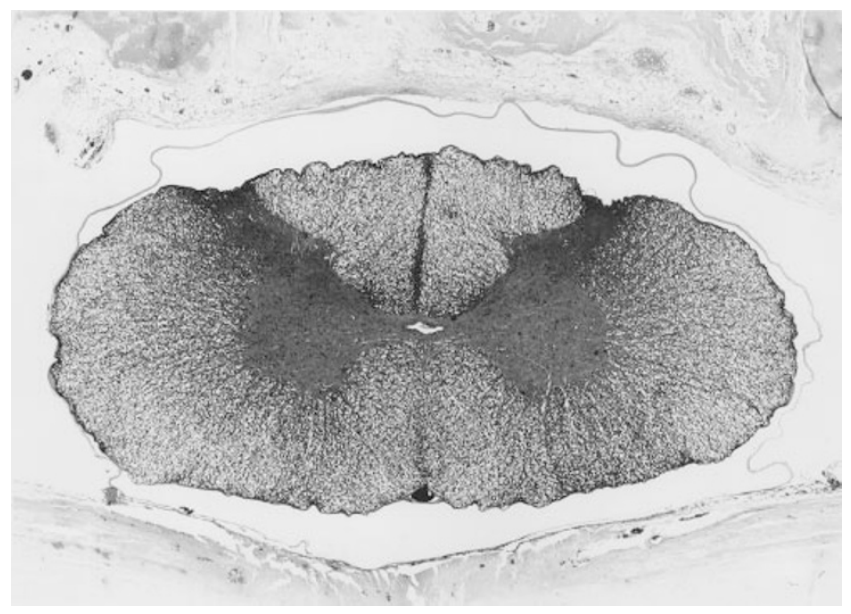

Figure 7 Transverse section of the cord at level of L5-6. No clear abnormalities were observed in flattened cord by light microscopic examination. H.E stained $\times 3$

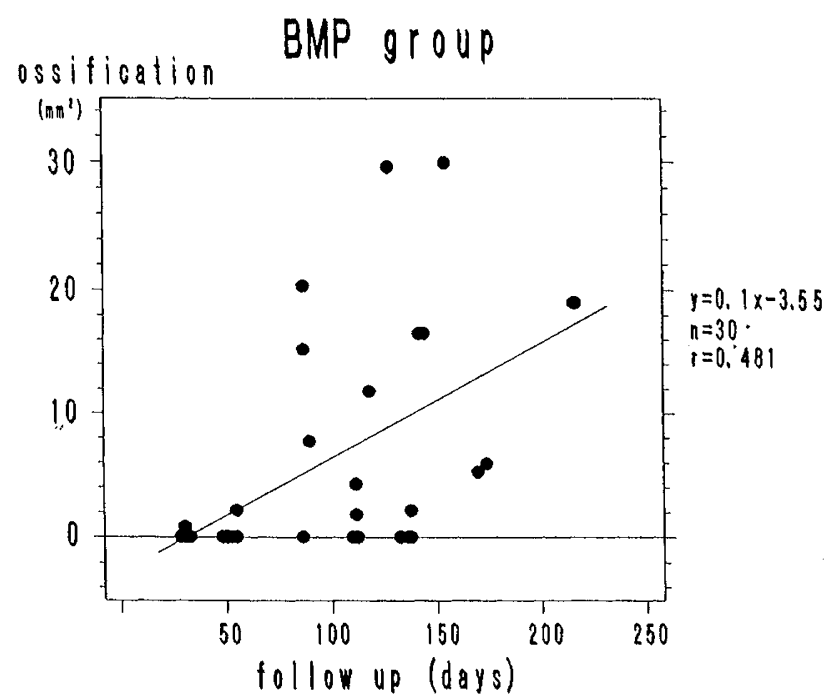

Figure 8 Correlation between follow up days and ossification 


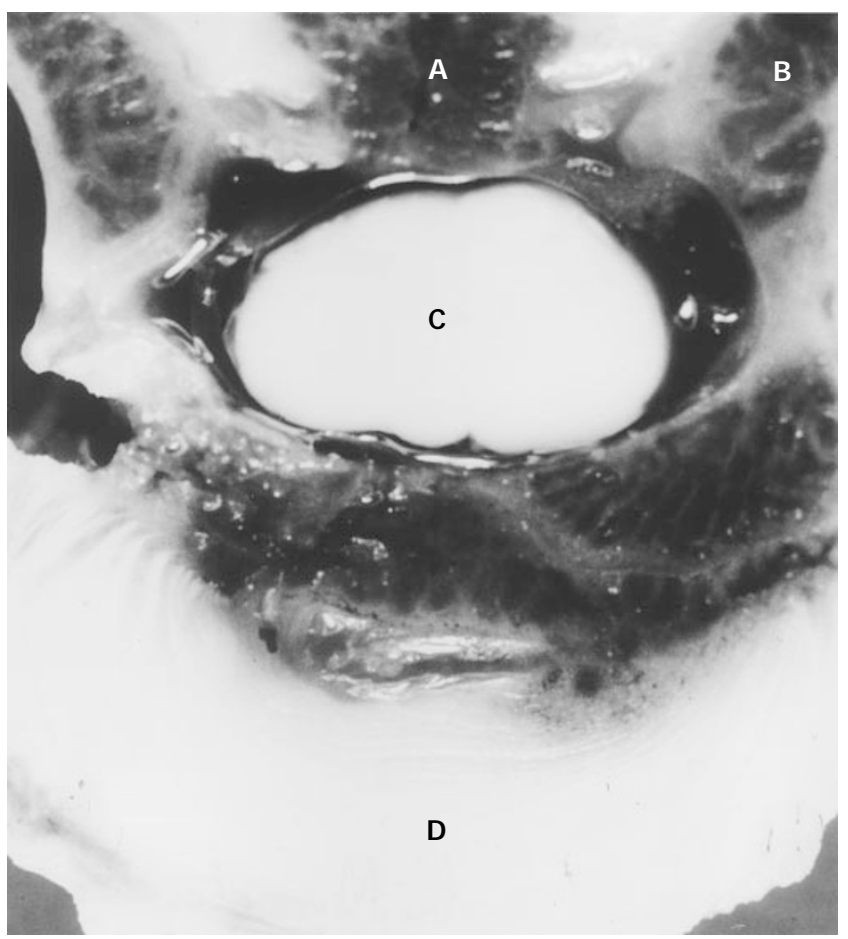

Figure 9 Large ossification (A) is seen in ligamentum flavum and dorsal column of BMP group. Case \#20. Flat ratio of the cord is $62.5 \%$. Motor palsy grade is 5. (B) transverse process (C) cord (D) intervertebral disc

ymal cells into cartilage cells, suggesting that in vivo it induces new bone formation by a process of endochondral ossification. ${ }^{13}$ Experiments in monkeys have confirmed that bone induction similar to that found in rats or rabbits occurs, indicating that the use of this substance may be possible in man as well. ${ }^{14}$ The fact that BMP induced endochondrial ossification in organ cultures of posterior longitudinal ligament or ligamentum flavum tissue also supports the contention that it may play a role in the ligament ossification occurring in vivo, and moreover it has been demonstrated experimentally in vivo to induce intraligament ossification. By implanting BMP within the ligamentum flavum it has been possible to establish models of ligamentum flavum ossification. ${ }^{15-17}$

Our purpose in the present study was to take advantage of the ossification action of BMP to induce chronic stenosis of the spinal canal in rabbit. In this experiment, screws or other artificial objects were not used to create chronic cord compression, but gradual compression was produced by naturally developing bone. However, the new bone did not reach the size that had been expected. Also, even when extensive ossification was achieved, it tended to extend dorsally without extending into the spinal canal or markedly compressing the cord (Figure 9). Accordingly, no rabbit while being maintained in a cage developed spinal palsy. Some animals were unable to run quickly or well, but this was attributed to their prolonged confinement in cages. When a burst fracture is treated conservatively, the bone fragments protruding into the spinal canal are absorbed and the spinal canal naturally expands. ${ }^{18}$ Considering that the spinal canal can also expand naturally, it can be understood that it is difficult to induce ossification into the spinal canal sufficiently to gradually compress the cord.

No pathological findings were noted in the flattened rabbit cord at least when examined under a light microscope. Intramedullary pathological changes in mice have been reported by Miyamoto et al. ${ }^{16}$ However, the degree of ossification differs in rabbits and mice, and extends less in the former. This is thought to be due to species differences between rabbit and mice.

We tried to enhance the possibility of the ossified material induced by the BMP becoming larger by placing it in contact with the cut down lamina and portion of the spinous process. Growth of bone to the ventral side was inadequate. Ossification under the lamina would be induced in Miyamoto's mice experiments because BMP was inserted into the epidural spaces under the ligamentum flavum. The manipulation of inserting BMP into the epidural space under the ligament is extremely difficult even when performed under a microscope, and we were concerned about injuring the spinal cord.

\section{Conclusion}

BMP induced ossification of the ligamentum flavum resulting in spinal canal stenosis in the rabbit, which is a species much larger than the mouse. Although no high-grade compression of the spinal cord was found, it was possible to create in rabbits a state of slight spinal cord compression. This model therefore reflects and will be useful in clarifying the early pathophysiology of chronic spinal cord compression.

\section{Acknowledgements}

Supported by a Grant-in-Aid for Scientific Research (No.B-1480366) from the Ministry of Education, Science, and Culture of Japan.

\section{References}

1 Fujino T. A microangiographic study of the experimental cervical spinal cord compression localized in the ventral aspect. J Jap Orthop Asso 1975; 49: 403-420.

2 Kurokawa T, Tanaka H, Seki H, Tsuyama H. Study on the cause of cervical spondylotic myelopathy. J Jap Orthop Asso 1975; 49: $769-771$

3 Ikata T et al. Experimental study in initial mechanism of OPLL. for cervical myelopathy animal model compressed by OPLL Study Group Report of Spinal Ossification in Japan Ministry of Welfare. 1987; 60-62.

4 Urist MR, Delange RJ, Finerman GAM. Bone cell differentiation and growth factors. Science 1983; 220: $680-686$. 
5 Wozney JM. Bone morphogenetic proteins and their gene expression. In: Noda M (ed.) Cellular and Molecular Biology of Bone. New York: Academic Press, 1993; 131-167.

6 Wozney JM. An overview of bone morphogenetic proteins. Spinal frontiers 1996; 3: 8-9.

7 Urist MR, Iwata H. Preservation and biodegradation for the morphogenetic property of bone matrix. J Theor Biol 1973; 38: 155.

8 Hanamura $\mathrm{H}$ et al. Solubilized bone morphogenetic protein (BMP) from mouse osteosarcoma and rat demineralized bone matrix. Clin Orthop 1980; 148: $281-290$.

9 Tarlov IM, Klinger H. Spinal cord compression studies. $A M A$ Arch Neurol and Psychiat 1954; 71: $271-290$.

10 Frankquist B, Schants B. Influence of extensive laminectomy on the spinal canal. Acta Orthop Scand Supplementum 1962; 56: 1 50

11 Cleste AJ et al. Identification of transforming growth factor $\beta$ family members present in bone-inductive protein purified from bovine bone. Proc Natl Acad Sci USA 1990; 87: 9843 - 9847.

12 Urist MR. Bone formation by autoinduction. Science 1965; 150: $893-899$.
13 Nogami H. Substrata prepared from bone matrix for chondrogenesis in tissue culture. J Cell Biol 1974; 62: 510-519.

14 Johnson EE, Urist MR, Finerman GAM. Distal metaphyseal tibial nonunion. Deformity and bone loss treated by open reduction, internal fixation, and human bone morphogenetic protein (h BMP). Clin Orthop 1990; 250: 234-240.

15 Kishi S, Saitoh H, Mimatsu K, Satoh K. Experimental study of spinal canal stenosis of the rabbit made by transplanted BMP after partial laminectomy. Study Group Report of Spinal Ossification in Japan Ministry Welfare (in Japanese), 1989. $77-79$.

16 Miyamoto S, Takaoka K, Yonenobu K, Ono K. Ossification of the ligamentum flavum induced by bone morphogenetic protein. J Bone Joint Surg 1992; 74-B: 279-283.

17 Murakami H. Experimental study on ossification of spinal ligaments in the rabbit under influence of bone morphogenetic protein. J Jpn Orthop Assoc 1988; 62: $1211-1220$.

18 Krompinger WJ et al. Conservative treatment of fractures of the thoracic and lumbar spine. Orthop Clin North Amer 1986; 17: $161-170$. 